\title{
THE ROLE OF SOCIAL SYSTEMS IN THE CONCEPTION AND PERPETUATION OF BULLYING CULTURE IN INDIA
}

\author{
Thseen NAZIR ${ }^{1} \quad$ Liyana THABASSUM²
}

\begin{tabular}{|c|c|}
\hline Article Info & \multirow{11}{*}{$\begin{array}{l}\text { Abstract } \\
\text { The pervasiveness of bullying in schools is a major concern that needs } \\
\text { to be addressed. Bullying culture involves a manifestation of the power } \\
\text { dynamics seen in a particular society. Despite the significant amount of } \\
\text { research conducted in this area, there is still a lack of literature } \\
\text { pertaining to bullying culture in India, especially involving the } \\
\text { victimization of children. Indian society feeds off on social inequalities } \\
\text { perpetuated by differences in class, caste, or religion. This sets the stage } \\
\text { for notable variations in power, and on this stage masquerades the } \\
\text { bullies. India finds itself with a bullying culture at different } \\
\text { organizational levels; from schools to big companies. Indian schools, } \\
\text { which represents a microcosm of society, is a direct reflection of the } \\
\text { power dynamics seen in society at large. A lack of research about } \\
\text { bullying in Indian schools opens the door to a wider range of concerns } \\
\text { that includes a lack of initiative taken by schools or parents to curb the } \\
\text { onslaught of bullying. This paper seeks to throw light on how this is the } \\
\text { case due to the misperceptions regarding bullying that society } \\
\text { propagates. For example, children and adults are often confused as to } \\
\text { what constitutes bullying because to them certain acts of bullying } \\
\text { mirrors traditionally accepted forms of disciplinary actions taken } \\
\text { against children. This paper reviews literature showing how children } \\
\text { are often misguided about what bullying is and the role that societal, } \\
\text { familial, or school structures play in perpetuating said misconceptions. } \\
\text { Furthermore, the paper also provides examples of certain non- } \\
\text { traditional forms of bullying that reflect the misguided perceptions that } \\
\text { children have about bullying. }\end{array}$} \\
\hline DOI: 10.35452/caless.2021.4 & \\
\hline Keywords & \\
\hline Bullying & \\
\hline Victimization & \\
\hline Parental attitudes & \\
\hline Sexual bullying & \\
\hline Corporal punishment & \\
\hline Received: 30.01.2021 & \\
\hline Accepted: 15.04.2021 & \\
\hline Published: 27.06.2021 & \\
\hline
\end{tabular}

Cited as APA: Nazir, T., \& Thabassum, L. (2021). The role of social systems in the conception and perpetuation of bullying culture in India. International Journal of Current Approaches in Language, Education and Social Sciences (CALESS), 3 (1), 69-82.

\footnotetext{
1 (D) Ibn Haldun University, Turkey, haroon.tehseen@gmail.com

2 (iD) Ibn Haldun University, Turkey, liyana.thabassum@ibnhaldun.edu.tr
} 


\section{Introduction}

21st century India has witnessed an expansion in its conversations regarding mental health. This is a massive win for a country in which mental health and seeking mental health services are still stigmatized to a great degree. Mental health professionals and academicians are going to great lengths to make sure that the change they envision as a mental health community will achieve its fruition among the public. Although unfortunately, this movement has yet to make an impact on the mental health services provided in schools, to children and parents alike, for therein lies the extremely prevalent issue of bullying and victimization.

Bullying can be defined as a systematic form of aggression based on an imbalance of power, the purpose of which is to harm or embarrass the victims (Olweus, 1993; Ayas, 2012; Chandran et al., 2019). The key features of which most authors would agree upon as follows; one, bullying roots from a power imbalance between the bully and the victim. This could be a perceived sense of superiority over others due to attributes of social class, caste, color, or gender. It could also be because of certain characteristics they consider merely to be 'better than' the rest. This sense of power leads bullies to believe that they are justified in their actions of administering a certain punishment or withholding resources from their victims (Olweus, 1993; Rubin et al., 2007). This intrinsic feature of bullying (power) is also, what sets it apart from other aggressive behaviors such as fights, quarrels, or teasing. Second, bullying behaviors repeat over time creating a vicious pattern of interaction between the bully and the victim (Olweus, 1993; Arseneault et al., 2010; Duy, 2013).

Various theories have tried to explain the perpetuation of bullying in schools. Organizational Culture Theory emphasizes the role that school culture/climate plays in perpetuating bullying behaviors. That is, the perpetuation of bullying vulture with the school depends on the values imparted by the students, teachers, administration, parents, and community (Pilch \& Turska, 2014). Another perspective comes from the Social Capital Theory, which posits the importance of social capital in perpetuating bullying culture. Social capital is the resources (social influence, social credentials, popularity, etc.) derived from social relationships. Bullies, already protected by their social status, perpetrate bullying behavior to maintain the power they already hold. Victims, on the other hand, are low in social capital and subject to continued victimization. Similarly, bully victims strive to end their victimization and acquire social capital by bullying weaker peers (Evans \& Smokowski, 2015). Fortunately, bystanders with high social capital can help reduce bullying perpetuation by engaging 
in prosocial acts (Jenkins \& Fredrick, 2017). Next, the Dominance theory propounds that bullying behavior is the result of a need for power/ dominance. Bullys maintain their social status by exerting dominance over those weaker than them (Evans \& Smokowski, 2015). This leads us to another related theory; the Theory of Humiliation, which explains how bullies to establish power/ dominance, often resort to shaming victims and relegating them to a lower social status (Evans \& Smokowski, 2015).

Over the years, different forms of bullying have been identified, with the main distinction being between direct and indirect/relational bullying (Arseneault et al., 2010). Duy (2013) has further listed physical bullying, verbal bullying, psychological bullying, and sexual bullying. The digitized world has also seen the rise of a new form of bullying called cyberbullying (Dilmaç \& Aydoğan, 2010). Direct bullying involves physical or verbal aggression where the victims are immediately aware of the identity of the bullies, whereas indirect/relational bullying involves concealed efforts at harming someone, such as with the use of threats or negative rumors about the victim (Malik \& Mehta, 2016). It is important to note that the visibility of bullying behaviors are important when it comes to identifying them as acts of bullying.

The Teacher foundation conducted a five-year survey in 15 locations in India and found that $42 \%$ of students from class $4-8$ and $36 \%$ of students from class $9-12$ reported as having been subjected to different forms of peer bullying at schools (Gyanesh, 2017). Another study conducted in randomly selected schools of rural India saw $31.4 \%$ of its 500 students reporting to having been bullied, with $16 \%$ having experienced physical or direct bullying, and only $24 \%$ of parents were aware of the bullying (Kshirsagar et al., 2007). Another study conducted in the state of Karnataka showed that $60.4 \%$ of the 500 children interviewed had experienced bullying, and only 65 parents were aware of it (Ramya \& Kulkarni, 2010). Despite the alarming rise of bullying incidents in schools, there exists a significant gap in the literature pertaining to bullying and victimization in Indian schools. Especially with regards to understanding the factors involved in the perpetuation of bullying culture.

Such a blind spot in the literature then affects the efforts made by mental health professionals in curbing bullying in schools. A major concern is to see whether children have an appropriate idea of what constitutes bullying and if they can accurately distinguish between bullying and what they consider "friendly teasing" or "forms of punishment." It is pertinent then to understand the factors that play a role in shaping their understanding of the concept and their attitude towards being bullied. This paper seeks to review literature that provides an insight into understanding this core issue, to understand the potential influences of culture, school systems, and 
parental attitudes as such in shaping the concept of bullying. This would subsequently provide us with an idea of how bullying behaviors are perpetuated and why children shy away from recounting their bullying experiences to adults. Furthermore, examples of non-traditional forms of bullying will be provided to illustrate the central idea that children require assistance with demarcating bullying behaviors from forms of teasing or disciplinary acts.

\section{Bullying from an Indian context}

India hosts a plethora of different cultures and languages, and on account of this distinctive feature, it is rare to see the word 'bullying' being used by the general public. Alternatively, cultural differences ensure the usage of specific terms for what each culture considers as bullying. Naturally, these terms may vary from culture to culture and language to language. For example; Tamil Nadu, a state in India uses the following terms Takkutal, Keli, Purakanital, to refer to physical, verbal, and relational bullying respectively (Campbell et al., 2018). On the other hand, Hindi, a language spoken in some parts of Northern India, uses the term Dadagiri (among others) to refer to bullying. Who are the bullies and who are the victims? This question has to be looked at from the vantage point of these different cultures. Naturally, it can be assumed that a North Indian child's conception of bullying and even his bullying experiences may vary greatly from that of a South Indian child. When studying bullying from an Indian context, apart from the colloquial terms given to the act of bullying, one generally comes across words such as 'ragging' and 'eveteasing'(Campbell et al., 2018). Ragging is a form of hazing that is central to schools and universities, wherein children are often harassed or bullied. This is unfortunately seen as a sort of initiation ritual for students and hence overlooked by authorities unless it becomes "drastic". Eve-teasing, on the other hand, is a term used to refer to acts of sexual harassment, stalking, etc. This variation in the nomenclature could be one of the reasons why there is a lack of literature localized in an Indian context.

Apart from this diversity in bullying culture across the nation, there are other cultural narratives at play in defining bullying. India is considered a collectivistic society at the societal level and individualistic at a people level (Harkness et al., 2000). Although the popular take on this issue points to India being collectivistic, as mentioned previously the heterogenic nature of this country makes it hard to give it such a unanimous title. At the same time, we cannot ignore the fact that many elements of a collectivistic society, such as cooperation and interdependence takes precedence in most communities of India, further acting as an aggravating factor for bullying 
within certain contexts (Malhi et al., 2015). A school context where children are encouraged to go along with each other no matter the harassment aimed at them so that everyone can continue with the lessons "in a peaceful manner", can be taken as an example for this.

Another cultural undertone that influences bullying culture is that of the deeply rooted sentiments of patriarchy (Campbell et al., 2018), which predicts how a particular society behaves. This sentiment makes it easier for people to tolerate aggressive behaviors, of which bullying is an example. 'Manliness' and aggression are used as a display of power and are implicitly accepted by a patriarchal society (Elsea \& Smith, 2000). This inevitably leads to the propagation of bullying culture, wherein victims are expected to take the brunt of this aggressive behavior without any complaint whatsoever. Patriarchic undertones can also be discerned from the way victimized children are expected to stand up for themselves without showing any form of weakness. This becomes even more relevant in cases where girls are the victims and boys the perpetrators. Power is wielded by the male to dominate or control the female, prescribe to her certain 'ways of behaving' and if she doesn't agree, then punish her (Corvo \& deLara, 2010).

A testament to class difference is the country's growing economy, which has furthered the divide between the rich and the poor, where the rich keep getting richer and the poor keep getting poorer (Pereira \& Malik, 2015; Campbell et al., 2018). Additionally, the cast system segregates people and children alike, creating an even greater social divide. There is an understanding among the masses that people are divided by religion, caste, and class, by money, power, and influence. This kind of distinction comes from India being a high power distance country as per Hofstede's cultural value dimensions (Campbell et al., 2018). This means that people are not equal, instead their place in society is determined by a social hierarchy. These kinds of social attitudes often lead to a power imbalance among children, further paving the way for bullying behaviors.

\section{Systems of influence: Family and School}

The role that family and school systems play in propagating bullying culture cannot be overlooked. Both these systems are quite important when it comes to the socialization process of children. According to Bandura's (1977) social learning theory, children learn social behaviors through observation. This can prove to be dangerous in contexts where the family or school systems accept violence and bullying as the norm (Corvo \& deLara, 2010). As such, social learning theory (Bandura, 1977) posits that bullying behavior is perpetuated by children who have experienced aggression 
themselves through observation. The traditional Indian family tries to infuse children with values of patriarchy, an understanding of social hierarchy, obedience to the 'more powerful', and interdependence (Jambunathan \& Counselman, 2002). Authoritarian parenting and violence within the family pave the way for children's understanding that power can be wielded against the weak and the weak should just suffer in silence (Corvo \& deLara, 2010; Campbell et al., 2018). Children born to authoritarian parents often discount their bullying experiences to incidents of mere 'teasing' or 'friendly fighting' (Malik \& Mehta, 2016). Parents are also known to teach their children avoidance or assertive behaviors as a way of responding to bullies, which may do more harm than good (Troop-Gordon \& Gerardy, 2012). Parents with normative views of bullying or violence can easily shape their children's conception of bullying to mirror their conceptions (Christie-Mizell, 2003; Mishina, 2004; Troop-Gordon \& Gerardy, 2012). These children grow up believing that their caste, religion, or class provides them with a better social standing than the others, paving the way for a power imbalance upon which bullying culture thrives.

As per social learning theory (Bandura, 1977), violence within schools can also perpetuate bullying culture. Indian schools have a reputation for dusting off bullying incidents under the rug, as the teachers themselves resort to using harsh disciplinary methods (Sreekanth, 2009). According to the general systems theory (Von Bertalanffy, 1968) schools make up a system that enables and perpetuates hostile and aggressive behaviors (deLara, 2006). Schools may also permit bullying culture (social control) to be maintained as they value discipline and require their children to conform to certain rules and regulations set by the school itself (Corvo \& deLara, 2010). Since bullying may require victims to conform to the majoritarian attitude (Kumar, 2019) or the proper code of behavior and dressing, schools turn a blind eye towards it. Another reason that teachers choose not to acknowledge bullying culture within schools is so that it doesn't negatively impact the school's reputation (Ramya \& Kulkarni, 2010). These factors inevitably lead to the perpetuation of a bullying culture within the system.

\section{What is considered bullying?}

Victimized children often find it hard to have an accurate understanding of what bullying entails. This could be because of the influence of socially propagated ideas about bullying. For example, Relational bullying is usually misidentified and therefore unreported by victimized children. According to a study by Mishna and colleagues (2006) majority of students, and adults alike, are aware that bullying entails 
a power imbalance and that it is an intentional act of aggression. What most of them aren't aware of is that indirect or relational forms of bullying, like social exclusion, or spreading of negative rumors, are also a form of bullying (Mishna, 2004; Nazir, 2019). A study done in India by Ramya and Kulkarni (2010), reported that indirect/relational bullying was the most common form of bullying experienced by children, including; name-calling (57.9\%), making fun of one's physical appearance $(15.5 \%)$, and degrading them (15.2\%). Despite it being the most experienced form of bullying only $39 \%$ of parents knew that their children were being bullied (Ramya \& Kulkarni, 2010). Social exclusion, which is another widely practiced form of relational bullying (Crick et al., 2006) is also not given as much importance as it should. Instead of reporting these forms of bullying experiences, children would rather suffer in silence to feel included by their peers (Corvo \& deLara, 2010).

Other bullying forms that children find hard to identify include the usage of corporal punishment in schools. Indian schools, especially public schools, lack enough resources to provide for their highly populated student community. Moreover, there is a significant shortage of teachers or school personnel, who have been properly trained to combat issues such as bullying. UNESCO reports that among children over the age of 8 , about nine in ten reported witnessing corporal punishment being used by a teacher in a week. Boys were more likely to experience corporal punishment, as girls were subjected to humiliating and sexual treatment/violence instead (Ogando Portela \& Pells, 2015). Corporal punishment is a norm in schools of India and often isn't considered as a form of bullying (Malhi et al., 2015). Morrow and Singh (2014) tried to discern the reasons for this and identified caste and class as significant factors in determining the frequency by which a student would get beaten by the teacher, with the lower class or caste reporting a higher incidence rate (Morrow \& Singh, 2014). Children believe that they are being punished for doing something wrong because corporal punishment does not fit into their idea of traditional bullying behaviors. Morrow and Singh (2014) go on to give an example of a child who was reported as saying, "They beat so that we learn and we are becoming big, but it hurts." Furthermore, the inclination that teachers and parents show towards victim-blaming can seriously impede a victim's choice of speaking up about the bullying (Mishna et al., 2006; Nazir, 2019).

Another conundrum faced by children and adults alike is the bully-victim. This concept is so unlike the traditional idea of bullying within the Indian society that people are unable to comprehend it. A bully victim is someone who has been bullied before and goes on to bullying others, thus taking on the roles of both a victim and a 
bully (Malik \& Mehta, 2016). These children try to compensate for the pain, humiliation, and frustration of being a victim, by inflicting the same pain onto others. Shame plays a huge role in the creation of the bully victim, who as a result of being shamed by their bully chooses to displace that anger onto others through similar aggressive behaviors (Corvo \& deLara, 2010). The concept of a bully victim has not been studied as much in an Indian context, adding to the confusion of how to deal with this category of children.

Sexual bullying is another category that children have a hard time identifying. That bullying can be overtly sexual seems to evade children and their care taker's minds. In this case, as well, children keep away from reporting sexual bullying because of patriarchic undertones in society or the belief that the bullies are just playing around. Nazir (2020) found that among high school children $0.2 \%$ of the boys and $0 \%$ of the girls from the sample reported being sexually bullied. A hesitation to report, born out of cultural barriers, was revealed to be the reason for such low numbers (Nazir, 2020). Society doesn't hold these bullies accountable for their actions, instead, they expect the victims to go through with the bullying as a part of 'growing up'(Leach \& Sitaram, 2007). Parents also discount sexual bullying faced by their children, by making it out to be isolated episodes of playful teasing. They go as far as to say that sexual bullying is a method used by bullies to express affection towards the victims (Mishna, 2004). Implicit messages such as 'boys will be boys' and prescribed gender norms that necessitate female compliance to a superior male authority are inculcated into the minds of the young victims, who then believe that what is happening to them is okay (Campbell et al., 2018; Chandran et al., 2019).

Then we have sibling bullying, a concept that may seem exaggerated and even overreaching at points because as a popular belief; sibling fights are normal. Sibling bullying has been defined as a systematic form of aggression aimed at another person (sibling) to cause physical or psychological harm (Chandran et al., 2019). Victimized children are taught to believe that this form of bullying is not a thing of concern by parents who normalize said behavior (Chandran et al., 2019). Children themselves have no inkling of the possibility the siblings can bully and hence they don't speak up about it.

Lastly, bullying among friends is also hard to be identified as an act of bullying (Mishna, 2004). This is because children, as they grow older, are more trusting of their friends as opposed to parents or teachers (Elsea \& Smith, 2000; Ramya \& Kulkarni, 2010). This, along with a need to belong are one of the main reasons why children 
choose not to go to the authorities. They end up believing they are being teased instead of being bullied and find it hard to distinguish between the two (Nazir, 2019). As mentioned previously, relational bullying, such as spreading negative rumors about friends, is misconceived as something other than bullying (Mishna et al., 2006). Taking cyberbullying as an example, it is again very easy for parents to disregard the abuse children receive online for a lack of physical harm done (Dilmaç \& Aydoğan, 2010). Similarly, children too are unaware that the mean comments that their children are receiving online are actually a form of indirect aggression and hence constitute bullying.

\section{Conclusion}

This paper attempts to provide a small part of the wider spectrum of bullying culture. No doubt, there is a need for a bigger audience to be aware of this issue as bullying is likened to normative displays of aggression in India. A vast majority of the Indian population comprises of children, and one of the major concerns to mental health faced by these children is school bullying (Jayakumar et al., 2019). Bullying is a very serious issue, which can affect the progress of a child socially, as well as academically (Nazir, 2015). Even though there are many studies on bullying, but there is a lack thereof pertaining to bullying in Indian schools specifically. Reasons for this can be many; poor infrastructure, poorly trained teachers, and the intense competition between private schools to ensure better academic achievement, to name a few.

Normative beliefs regarding bullying/aggressive behaviors result in a child's inability to gain the emotional support that they desperately need in order to navigate through bullying experiences (Troop-Gordon \& Gerardy, 2012). When children feel that their experiences of bullying are not being validated by their caregivers, they may learn inappropriate and unhealthy responses to deal with said experiences. Not having a safe spot to anchor oneself to, while treading through turbulent waters can cause a person to lose themselves, and the same can be said for a child victim who lacks support from parents, teachers, and peers. Therefore, it is extremely important to address the issue of bullying at a societal level, taking into consideration the cultural values that play a role in perpetuating bullying.

As established already, bullying is a learned behavior, and as such can be unlearned through positive parental cues that trump the aggression victimized children have witnessed. A supportive school environment has been associated with student's academic growth, positive engagement, and overall wellbeing in school (Gregory \& Weinstein, 2004; Gregory et al., 2010). Proper training needs to be given to teachers to be able to handle the pressure of crowded schools, enabling them to have 
a positive role in their student's life. A supportive school environment also ensures that children are more willing to share their bullying experiences and seek help (Gregory \& Weinstein, 2004). Such an environment will inevitably cultivate students who value the school's rules, thereby reducing the pressure on teachers to use extreme disciplinary methods. Zero-tolerance policies when it comes to maintaining order can bring about the same results in children as with authoritarian parenting.

When it comes to private schools, the Central Board of Education maintains that all schools should have an Anti-bullying committee set up. These committees should operate in the presence of a counsel to monitor bullying in schools, provide awareness to students, and help both the victims and bullies in getting through their ordeals. Unfortunately, though, most schools do not have such a specific committee set up, nor do they have a school counselor present for monitoring bullying. This is especially so for government schools running on low funds. Furthermore, the consequence of expulsion or suspension rarely helps in curbing bullying among children and can even lead to aggravated bullying. Therefore, better laws must come into place that focuses on rehabilitating bullies rather than just expelling or punish them.

Intervention needs to be based on a multi-component system that takes into account all the systems of influence in a child's life, starting from family, to friends, to teachers. Intervention strategies should start at a community level, focusing on schools and the overarching cultural values that perpetuate bullying culture. The second stage should involve active communication between a child's close circuit relationships, such as between teachers, parents, friends, peers, etc. Parent-Teacher Association (PTA) is a set up that allows for communication between schools and parents, wherein it becomes possible to understand a child's situation at home and school. This keeps both parents and teachers in the loop for possible bullying that may happen within the school or family settings. These PTA meetings are to be enforced ceremoniously in schools. Measures should be taken and ensured in schools across the country, in government and private institutions.

Lastly, intervention strategies aimed at inculcating positive and enduring coping mechanisms are also of the utmost importance. Ultimately taking away the root cause of the problem is not just enough; instead, victims and bullies must be equipped with strong mental resources that will help them in the future. In this way, the possibility of victims becoming bullies (bully-victims) later on is also reduced. Intervention should be aimed at every component in a child's life that facilitates and aggravates the bullying culture. Awareness programs aimed at not just the parents, 
teachers, and students, but also the public is of the essence in curbing bullying. It requires a community effort to topple the belief and value systems that inevitably strengthen misconceptions about bullying.

\section{References}

Arseneault, L., Bowes, L., \& Shakoor, S. (2009). Bullying victimization in youths and mental health problems: "Much ado about nothing"? Psychological Medicine, 40 (5), 717-729. https://doi.org/10.1017/s0033291709991383

Ayas, T. (2012). The effect of parental attitudes on bullying and victimizing levels of secondary school students. Procedia- Social and Behavioral Sciences, 55, 226-231. https://doi.org/10.1016/j.sbspro.2012.09.498

Bandura, A. (1977). Social learning theory. Englewood Cliffs.

Campbell, M., Kettle, M., \& Sundaram, S. (2018). Societal and cultural considerations in understanding peer bullying in India. Bullying, cyberbullying and pupil well-being in schools: comparing European, Australian and Indian perspectives, 26-44. https://doi.org/10.1017/9781316987384.003

Chandran, S., Prakrithi, S., Guru Prakash, K., \& Kishor, M. (2019).Bullying in Incognito Mode: The evolution of sibling bullying. Indian Journal of Social Psychiatry, 35(2), 142. https://doi.org/10.4103/ijsp.ijsp 4418

Christie-Mizell, C. A. (2003). Bullying: The consequences of interparental discord and child's self-concept. Family Process, 42(2), 237-251. https://doi.org/ 10.1111/j.1545$\underline{5300.2003 .42204 . x}$

Corvo, K., \& deLara, E. (2010). Towards an integrated theory of relational violence: Is bullying a risk factor for domestic violence? Aggression and Violent Behavior, 15(3), 181190. https://doi.org/10.1016/j.avb.2009.12.001

deLara, E. (2006). Bullying and violence in American cchools. Handbook of Children, Culture, and Violence, 333-354. https://doi.org/10.4135/9781412976060.n17

Dilmaç, B., \& Aydoğan, D. (2010). Parental attitudes as a predictor of cyber bullying among primary school children. World Academy of Science, Engineering and Technology, 67, 167-171.

Duy, B. (2013). Teachers' attitudes toward different types of bullying and victimization in turkey. Psychology in the Schools, 50 (10), 987-1002. https://doi.org/ 10.1002/pits.21729 
Eslea, M., \& Smith, P. K. (2000). Pupil and parent attitudes towards bullying in primary schools. European Journal of Psychology of Education, 15(2), 207-219. https://doi.org/10.1007/bf03173175

Evans, C. B. R., \& Smokowski, P. R. (2015). Theoretical Explanations for Bullying in School: How Ecological Processes Propagate Perpetration and Victimization. Child and Adolescent Social Work Journal, 33 (4), 365-375. https://doi.org/10.1007/s10560-015-0432$\underline{2}$

Gredler, G. R. (2003). Olweus, D. (1993). Bullying at school: What we know and what we can do. Malden, MA: Blackwell Publishing, 140 pp., \$25.00. Psychology in the Schools, 40(6), 699-700. https://doi.org/10.1002/pits.10114

Gregory, A., Cornell, D., Fan, X., Sheras, P., Shih, T.-H., \& Huang, F. (2010). Authoritative school discipline: High school practices associated with lower bullying and victimization. Journal of Educational Psychology, 102(2), 483-496. https://doi.org/10.1037/a0018562

Gregory, A., \& Weinstein, R. S. (2004). Connection and regulation at home and in school. Journal of Adolescent Research, 19(4), 405-427. https://doi.org/10.1177/0743558403258859

Global Database on Violence against Women- India. (n.d.). UN Women. https://bit.ly/2QwWOLD

Gyanesh, A. (2017, July 28). 42 per cent of kids bullied at schools, says survey. The Times of India.https://bit.ly/2QurF0b

Harkness, S., Super, C. M., \& Tijen, N. V. (2000). Individualism and the "Western mind" reconsidered American and Dutch parents' ethno theories of the child. New directions for child and adolescent development, 2000(87), 23-39. https://doi.org/10.1002/cd.23220008704

Jambunathan, S., \& Counselman, K. (2002). Parenting attitudes of Asian Indian Mothers Living in the United States and in India. Early Child Development and Care, 172(6), 657-662. https://doi.org/10.1080/03004430215102

Jayakumar, C., Ranjith, Pj., Kishore, Mt., Binukumar, B., \& Bhaskar, A. (2019). Association between bullying, peer victimization and mental health problems among adolescents in Bengaluru, India. Indian Journal of Social Psychiatry, 35(3), 207. https://doi.org/10.4103/ijsp.ijsp 619 
Jenkins, L. N., \& Fredrick, S. S. (2017). Social capital and bystander behavior in bullying: Internalizing problems as a barrier to prosocial intervention. Journal of Youth and Adolescence, 46(4), 757-771. https://doi.org/10.1007/s10964-017-0637-0

Kshirsagar, V. Y., Agarwal, R., \& Bavdekar, S. B. (2007). Bullying in schools: prevalence and short-term impact. Indian pediatrics, 44(1), 25. http://www.indianpediatrics.net/jan2007/25.pdf

Kumar, R. (2019, May 07). A teacher's thoughts on our new national culture of bullying. The Wire. https://thewire.in/rights/bullying-india-hate-bigotry

Leach, F., \& Sitaram, S. (2007). Sexual harassment and abuse of adolescent schoolgirls in South India. Education, Citizenship and Social Justice, 2(3), 257-277. https://doi.org/10.1177/1746197907081262

Malhi, P., Bharti, B., \& Sidhu, M. (2015). Peer victimization among adolescents: Relational and physical aggression in Indian schools. Psychological Studies, 60(1), 7783. https://doi.org/10.1007/s12646-014-0283-5

Malik, A., \& Mehta, M. (2016). Bullying among adolescents in an Indian school. Psychological Studies, 61(3), 220-232. https://doi.org/10.1007/s12646-016-0368-4

Mishna, F. (2004). A qualitative study of bullying from multiple perspectives. Children $\mathcal{E}$ Schools, 26(4), 234-247. https://doi.org/10.1093/cs/26.4.234

Mishna, F., Pepler, D., \& Wiener, J. (2006). Factors associated with perceptions and responses to bullying situations by children, parents, teachers, and principals. Victims $\mathcal{E}$ Offenders, 1(3), 255-288. https://doi.org/10.1080/15564880600626163

Morrow, V., \& Singh, R. (2014). Corporal punishment in schools in Andhra Pradesh, India: Children's and parents' views. Young Lives.

Nazir, T., \& Piskin, M. (2015). School bullying: Effecting childs mental health. The International Journal of Indian Psychology. 2(4), 130-135. https://bit.ly/3euIKzi

Nazir, T. (2019). Prevalence of school bullying in higher secondary school students and myths related to bullying among students. Journal of Advances and Scholarly Researches in Allied Education. 16(4), 5. https://bit.ly/3sP9ZJM

Nazir, T. (2020). Okul zorbalı̆̆ı: Okulda bir korku. Lambert Academic Publishing.

Ogando Portela, M. J., \& Pells, K. (2015). Corporal punishment in schools longitudinal evidence from Ethiopia, India, Peru and Viet Nam. UNICEF Office of Research, Florence, Italy (2015) 48 pp. 
Pereira, V., \& Malik, A. (2015). Making sense and identifying aspects of Indian culture(s) in organisations: Demystifying through empirical evidence. Culture and Organization, 21(5), 355-365. https://doi.org/10.1080/14759551.2015.1082265

Pilch, I., \& Turska, E. (2014). Relationships Between machiavellianism, organizational culture, and workplace bullying: Emotional abuse from the target's and the perpetrator's perspective. Journal of Business Ethics, 128(1), 83-93. https://doi.org/10.1007/s10551-014-2081-3

Ramya, S. G., \& Kulkarni, M. L. (2010). Bullying among school children: Prevalence and association with common symptoms in childhood. The Indian Journal of Pediatrics, 78(3), 307-310. https://doi.org/10.1007/s12098-010-0219-6

Rubin, K. H., Bukowski, W. M., \& Parker, J. G. (2007). Peer interactions, relationships, and groups. Handbook of Child Psychology. https://doi.org/10.1002/9780470147658.chpsy0310

Sreekanth, Y. (2009). Bullying: an element accentuating social segregation. Education 313, 37(3), 233-245. https://doi.org/10.1080/03004270802349463

Troop-Gordon, W., \& Gerardy, H. (2012). Parents' beliefs about peer victimization and children's socio-emotional development. Journal of Applied Developmental Psychology, 33(1), 40-52. https://doi.org/10.1016/j.appdev.2011.10.001

Von Bertalanffy, L. (1993). General system theory: Foundations, development, applications (No. BOOK). Georges Braziller, Inc. 